Boise State University

ScholarWorks

$10-1-2011$

\title{
Motivation, Goal Orientation, Coaching, and Training Habits of Women Ultrarunners
}

Rhonna Z. Krouse

College of Western Idaho

Lynda Ransdell

Boise State University

Shelley M. Lucas

Boise State University

Mary Pritchard

Boise State University 


\title{
Motivation, Goal Orientation, Coaching, and Training Habits of Women Ultrarunners
}

\author{
Rhonna Krouse, M.S. \\ College of Western Idaho
}

\author{
Lynda Ransdell, Ph.D., FACSM, CSCS, Shelley Lucas, Ph.D., and Mary Pritchard, Ph.D. \\ Boise State University
}

\begin{abstract}
Ultrarunners participate in running events that exceed the 26.2 mile marathon distance (e.g., 50 K, 50-100 miles). Very little research exists on ultrarunners, especially women. The present study is a descriptive study detailing the motivation, goal orientation, demographic characteristics (e.g., age, job demands, family structure), training habits (e.g., hours per week of training), and coach utilization of women ultrarunners. Participants $(N=344)$ were recruited via the Ultra Listserve and four popular ultrarunning websites, and they completed a questionnaire on motivation, goal orientation, training, and coaching using Survey Monkey. General health orientation (mean \pm SD) $(4.71 \pm 1.06)$ and psychological coping $(4.71 \pm 1.03)$ were the two strongest motivational factors. Participants were higher in task-orientation (1.38 \pm .68) (e.g., finishing the race or accomplishing various goals) than ego- orientation (3.38 \pm 1.01) (e.g., placing in the top 3 overall or beating an opponent). Women trained an average of 12.49 hours a week and spent $64 \%$ of their time training alone. Training information came from their own experience, blogs, websites, and the Ultra List Serve. Over three-fourths of the participants (80\%) did not use a coach because of cost and a perceived lack of necessity. Women ultrarunners in this study were task-oriented, internally motivated, health and financially conscious individuals. With additional information about women ultrarunners, coaches will be better prepared to work with this population and ultrarunners can improve their performance by learning about current participants' practices.
\end{abstract}

Keywords: female ultrarunners, ultra-endurance events, conditioning, female distance runners, long distance running

\section{Introduction}

Ultrarunners participate in cross-country foot races that exceed the traditional marathon distance of 26.2 miles (3). The most common distances are 50 kilometers, 50 miles, and 100 miles. Ultramarathons can be held on or off-road and they are typically designed to cover a specific distance or achieve a maximum distance within a designated time period. These races are generally characterized by severe course conditions, such as rough terrain, elevation changes, and inclement weather.

Ultramarathons have a long history in the United States and many other countries in Europe, Asia, and Africa. Although it is estimated that 70,000 people participate in ultrarunning around the world, it is difficult to pinpoint actual numbers because the American Ultrarunning Association (AUA) does not require membership, nor does it account for participants in other countries. Ultrarunning in the United States is relatively popular. For example, the Western States Endurance Run, which requires a lottery system to gain entry, has had over 10,000 participants since its official inception in 1978. The number of participants in other popular American ultrarunning events in 2008 ranged from 89 in the Forest Park 50K to 446 in the Leadville 100-miler. As the sport has grown in popularity--the number of races has tripled since the 1980s--so has the number of women participants. The estimated percentage of women competing in ultrarunning events has grown six-fold from $4 \%$ in the early 1980s (when women were banned from entering longer international distance races) to $27 \%$ in 2008 (12) 
To date, scholars have examined psychological issues such as personality, motivation, and goal orientation in endurance athletes and recreational athletes $(8,9,11)$. For example, researchers have concluded that women's motivation to exercise recreationally stems from a desire to lose weight, become fit, and/or gain social affiliation $(8,9,11)$. This brand of motivation, often identified in recreational athletes, is known as the "Social Motivation Model" (20,24). Conversely, women who participate in sports competitively, but not necessarily at the elite level, cite achievement, personal accomplishment, and empowerment as their motivational factors $(14,18)$. Motivation based on the desire to show competence, success, and achievement follows a theory known as "Achievement Goal Theory." What motivates an individual to participate in sports or recreational exercise can also influence the types of goals they set $(8,9,11,14,18)$.

Recent studies on marathon running demonstrate a convergence of the common motivational factors found in recreational exercisers and competitive participants. Although marathon running is considered a competitive sport, current studies show that women marathoners frequently cite motivational factors such as social affiliation, recognition, and gaining physical fitness more often than achievement and personal accomplishment $(20,24)$. Women tend to place their exercise needs below those of their spouse and children, and women with children are less likely to participate in exercise altogether $(8,28)$. If we can better understand the factors that motivate women ultrarunners, we can set more effective training goals and possibly develop strategies to target individual athletes-based on race distance. This understanding is particularly crucial for the scientific community (i.e., coaches, trainers, and so forth) who will be working with this growing population.

In addition to understanding motivational factors related to ultrarunning, it is important to examine the use of goal setting in this population. Past research demonstrates that just setting goals can help an athlete focus on the competition or event ahead $(5,6)$. In addition, goal setting can help an athlete perform successfully $(5,21,27)$. Ultrarunners, like other athletes, are governed by specific motivational components that define the goals they set for competition and overall commitment to the sport. A discussion of motivation must include the goals set for racing. Ultrarunning differs from many sports in that completion of the event can be considered as much of a success as winning. The sheer vigor and determination it takes to complete an ultramarathon is an important consideration for those who compete in this sport and for those who coach athletes in this sport. Knowing what type of goals women ultrarunners set should help aspiring ultrarunners and their coaches develop more specific, measurable, and attainable goals.

Finally, no previous studies have examined demographic characteristics, training habits, or coach utilization of ultrarunners. There is a need to understand the demographic characteristics of this population that finds significant time to exercise. Additionally, knowledge about current training habits, intersected with proper training techniques, has the potential to enhance performance in these ultrarunners. Thirdly, it is important to examine coaching practices in ultrarunning because proper coaching has helped athletes improve their performances through designing training regiments for specific physiological adaptations and facilitating mental preparedness in a variety of sports $(4,22)$. It is logical that the use of coaching with ultrarunners might impact their performance; therefore, knowledge about current practices in coaching will be beneficial.

Although distance runners and other endurance athletes have been the subject of biophysical, psychological, and sociological research, $(1,13,16)$ very few published studies have examined ultrarunners $(2,10,29)$, and only one study has examined women ultrarunners (12). A recent qualitative study of eight high-performing female ultrarunners shows important distinctions between ultrarunners and other distance runners (e.g., marathoners) (12), indicating a need for additional research on this unique population of athletes. Given the lack of published information about this sport, particularly about women ultrarunners, the purpose of this descriptive study was to create a profile of women ultrarunners by examining: (a) motivation, (b) goal orientation, (c) demographics (e.g., age, job demands, family structure, etc.), (d) training habits (e.g., hours per week of training), and (e) use of coaching. This profile will provide a valuable resource to practitioners (e.g., coaches, strength and conditioning specialists) working with this unique, relatively unknown, and growing population of athletes. 


\section{Methods}

\section{Experimental Approach to the Problem}

The purpose of this study was to explore various aspects of women ultrarunners, a population of athletes that has been infrequently studied. Thus, rather than using an experimental design, this study was a cross-sectional descriptive study that queried participants on surveymonkey.com about their motivation for participation, the goals they set, training habits, and utilization of a coach. These variables were selected because they are commonly examined in other endurance athletes, and because understanding these factors should help ultrarunners increase their success. In addition, understanding training habits and coach utilization patterns may help aspiring coaches break into this potentially untapped area of coaching. As we were merely gaining insight into ultrarunners' motivation for participation, the goals they set, training habits, and utilization of a coach, we asked them to respond to these questions generally and not for a specific ultrarunning event.

\section{Subjects}

Subjects $(N=344)$ in this study were adult women ultrarunners 18 years and older $(40 \pm 9$ yr $)$. They were recruited by sending solicitation emails to the Ultra List Serve (www.ULTRA@LISTSERV.DARTMOUTH.EDU) which has over 2,100 subscribers. Additionally, participants were solicited through five popular ultrarunning and trail running websites:

- Extreme Ultrarunning (http://www.extremeultrarunning.com/)

- Run More Talk Less (http://runmoretalkless.blogspot.com/),

- Pacific Coast Trail Runs (http://www.pctrailruns.com/)

- Santa Barbara Athletic Association (http://www.sbrunning.org/)

- A Trail Runners Blog composed by Scott Dunlap, the 2004 champion of the Trail Runner trophy series (http://runtrails.blogspot.com/).

Approval for the project was obtained from the university's institutional review board prior to starting data collection, and it was assumed that the subjects consented to participate when they completed the questionnaire for this study.

\section{Procedures}

Data Collection. Participants were asked to click on the following surveymonkey.com website (www.bkrousedemographics.com/RZL/ultrarunning.html) and fill out the questionnaires. Survey Monkey is an online survey website that allows researchers to develop surveys and create an email or website link so the survey can reach a mass audience via the internet. Data were collected and stored by Survey Monkey.

Questionnaires. Participants began by completing a simple researcher-developed questionnaire designed to learn about the sample studied and to obtain demographic information. This questionnaire asked participants about age, family, career, training schedule, goals, training resources, and utilization of a coach. All questions were multiple choice, fill in the blank, and open-ended. The questionnaire is available from the first author upon request and examples of questions are outlined in the data analysis section. Content validity was ascertained by using existing literature from other endurance-oriented sports to formulate the questions and by having a committee of experts read and critique the questionnaire.

Factors that contribute to motivation were measured using the Motivation on Marathon Running Scale (MOMS) (19). This questionnaire has been deemed valid and reliable for marathon runners with sufficient internal consistency (Cronbach's alpha range .80 to .93), test re-test reliability, (interclass Rs range .71 to .90), and factorial validity of the scales (19). In addition to its extensive use with marathon runners, it is currently the only questionnaire that has measured running motivation in ultramarathoners (29). 
The MOMS questionnaire consists of 56 questions. Participants were asked to "rate each of the following items according to the scale below in terms of how important it is as a reason for why you run." The rating system used a Likert scale ranging from 1 to 7 with a score of 1 indicating the item is "not a reason" for running and a score of 7 indicating that the item is a "very important reason" for running.

This questionnaire divides motivation into four categories, each with sub categories to allow for a close evaluation of motivational factors. These four categories include: physical health motives- general health orientation and weight concern; social motives- affiliation and recognition; achievement motives- competition and personal goal achievement; and psychological motives- psychological coping, self-esteem, and life meaning. A high mean score in any category represents a strong motivation to run (i.e., a high score in the achievement motives category means competition and personal goal achievement are significant motivators for the individual to run).

To measure goal orientation, the Perception of Success Questionnaire (PSQ) was used (26). Content validity for this questionnaire was established through repeated evaluation by an expert panel consisting of motivation researchers and sport psychologists who were accomplished in achievement goal theory. Cronbach's alphas for the task and ego scales were .89 and .90 , and test re-test reliability were $r=.97$ and .98 , respectively (26).

To determine goal orientations, participants were asked: "When racing in an event, I feel most successful when,” followed by a series of 12 questions designed to distinguish between a task or ego orientation. Each question was measured on a 5-point Likert scale where 1 signified that the participant "strongly agreed" with the statement, three represented a neutral feeling, and 5 indicated that the participant "strongly disagreed." For scoring, the questions were separated into a task or ego category. Each category contained six questions. A low mean score in either category represented a strong orientation with a score of three being neutral.

In addition to assessing goal orientation, it was helpful to ascertain the types of goals set for racing. Three openended questions were included on the demographic questionnaire to learn about the kinds of goals women ultrarunners set for competition:

- Do you train for races with a specific goal in mind?

- $\quad$ Give an example of two common goals for racing that you set (e.g., age group placing, run a specific distance within a certain time).

- What percentage of the time do you reach your goals?

Statistical Analysis. Since this was a descriptive study, no inferential statistics were used, nor did we test hypotheses. To examine motivation for participating in ultramarathons, means and standard deviations for each motive subcategory on the MOMS scale were calculated. Any motivation subcategory scale with a mean score of four or more was considered a primary motive for running (24). Goal orientation (i.e., task or ego orientation) was examined by calculating means and standard deviations for each goal orientation type. In addition, we describe the women's top goal categories. Internal consistency (Cronbach's alpha) was calculated for the MOMS scale and the PSQ (goal orientation scale). Participant demographics such as age, relationship/parenting/work status, and state of residence were calculated and reported as percentages in each category. Training habits were assessed by calculating the mean hours per week of training, as well as the percentage of women who trained with partners and/or utilized a coach. Finally, percentages were calculated representing common places women got their training information.

\section{Results}

Participant Demographics. Participants for this study were from thirty-five states. The states with the largest number of participants were California, Oregon, Washington, Colorado, Texas, and Virginia. A surprising number were from other countries including Canada, England, and Bolivia. Additional demographic characteristics are presented in Table 2. Preferred race distance did not very greatly between the participants with 32.6\% focusing on 50ks, 39.5\% participating in 50 mile distance, and 27.9\% racing primarily 100 mile distances. Subjects who focused on 50 and 100 mile distances reported participating in shorter events as well. Many of the participants who focused on the $50 \mathrm{k}$ reported a desire to complete greater distances in the future. 
Over three quarters (78.9 \%) of respondents reported being married or in a long-term relationship. When asked if their significant other participated in ultrarunning, only $29.5 \%$ said yes. However, 37 participants whose spouse or significant other was not an ultrarunner, did participate in other endurance sports (i.e., marathon running, mountain biking, road cycling, and triathlon).

Interestingly, $40 \%$ of the women reported having children and only 54 women had children under the age of six $(3.15 \pm 1.55 \mathrm{yr})$. There were 118 women who reported having children between the ages of six and eighteen (11.13 $\pm 3.27 \mathrm{yr})$ and 93 women had children who were over the age of eighteen $(26.46 \pm 6.42 \mathrm{yr})$.

The majority (75.7 \%) of subjects classified their work status as full-time averaging $41.02 \pm 11.07$ hours a week. For women who reported a range of hours worked (i.e., 35-45 hours a week), the mean was used to determine their hours worked. Women who were full-time students $(n=2)$ and stay at home mothers $(n=5)$ were included in the full -time employment category because of the number of hours typically spent completing the responsibilities that accompany those roles. Almost one fifth of the sample (16.1\%) worked part-time, with the remaining $8.2 \%$ not employed. Most women indicated that their jobs were not flexible and they designed their training schedule around work to achieve the necessary training hours.

Motivation. To examine motivation for participating in ultramarathons, the categories and subcategories with the highest and lowest scores were identified. Means and standard deviations were calculated for each category and subcategory, as shown in Table 1. The highest overall motivation category scores were for physical health motives $(4.80 \pm 1.02)$, indicating that physical health concerns related to health and weight were important sources of motivation, although health motives were rated higher than weight motives. Psychological motives (4.74 \pm 1.00$)$ scores were also high, indicating that self-esteem, life coping, and life meaning were also important sources of motivation in this group. The category of achievement motives was interesting in that it produced the highest subcategory score (personal achievement, $5.19 \pm 0.97$ ) and the lowest subcategory score (competition, $2.88 \pm 1.40$ ). Women ultrarunners in this sample were highly motivated by personal achievement but competition was not an important source of motivation. The lowest category score was for social motives $(3.57 \pm 1.19)$ and the lowest subcategory score was for recognition $(2.94 \pm 1.43)$ indicating that running for recognition was not a primary source of motivation. Interestingly, affiliation, (a subcategory within the social motives area), received a score of $4.19 \pm$ 1.37, indicating that it is a source of motivation in this sample.

To evaluate the internal consistency of the of the MOMS questionnaire, Cronbach's alpha was calculated for all categories (weight concern $(r=.85)$, health orientation $(r=.84)$, social recognition $(r=.90)$, social affiliation $(r=$ .85), competition $(r=.84)$, personal goal achievement $(r=.78)$, self-esteem $(r=.82)$, life coping $(r=.89)$, and life meaning $(r=.85)$ ). All categories except personal goal achievement had acceptable internal consistency $(r \geq .80)$, which is similar to past research (19).

\section{[Insert Table 1 about Here]}

Goal Orientation and Goal Setting. The first step toward evaluating goal orientations was to determine the means and standard deviations for both task $(1.38 \pm .68)$ and ego $(3.38 \pm 1.01)$ orientation goal categories. It appears as if this sample is more task-oriented than ego-oriented. The internal consistency (Cronbach's alpha) of the PSQ was acceptable for the categories of task $(r=.93)$ and ego $(r=.89)$ orientation and these findings are consistent with past tests of internal consistency (26).

Most of the participants $(85.2 \%, n=271)$ set goals for their chosen events. Only $14.8 \%(n=47)$ did not set specific goals. Twenty participants did not answer the question with a "yes/no" to goal setting, but chose to write the type of goals they set in the short answer section of the question. Goals set by participants fell into four goal categories: top finisher, time, distance, and strong completion.

The top finisher type included goals of age group placing, overall placing, and top percent in women (i.e., top 10\% or top five women to cross the finish line). The second type of goal revolved around finishing a distance within a given time. For some women, a time goal meant making the cutoff time to complete the race and for others it was 
about completing a previously raced course in a faster time. Women also set time goals for courses they had not yet run but still desired to achieve a certain time. Distance goals focused on completing new distances or finishing a difficult course. To illustrate, racing terrain varies so greatly that a $50 \mathrm{k}$ in one area can take ten hours to complete and a 50k race in a different area can take as few as five hours. The final type of goal set by participants was to finish the race, which included goals of being pain and injury free, ingesting proper nutrition, completing the race feeling strong, and enjoying the experience. When participants were asked to articulate the percentage of time they reach their desired goal, on average, they reached their goals $80 \%$ of the time.

Training and Coach Use. To evaluate training consistencies and variations between female ultrarunners, four main variables were analyzed: (a) hours spent training, (b) training partners (if any), (c) where they get their training information, and (d) if they utilize a coach. Women trained an average of $12.49 \pm 5.20$ hours a week. If participants reported a range of hours (i.e., 7-10) the mean value of the range was used in the analysis. There was a wide range of training hours reported, from as few as three hours a week to as many as 37.5. Two training values (55 and 50 hours) were removed from the analysis because they appeared to be outliers (i.e., participants may have confused mileage covered in a week instead of time).

In terms of training partners, $16.1 \%(n=55)$ trained solely by themselves, $3.8 \%(n=13)$ trained only with others, and $80.1 \%(n=274)$ trained alone and with others. For those who trained alone and with others, the average percentage of time spent training alone was $64.0 \%$ with percentages of time ranging from $2 \%$ to $99 \%$ of the time $(S D=26.14)$; the average time training with others was $35.3 \%$ with percentages of time ranging from $1 \%$ to $98 \%$ $(S D=25.92)$.

Sources of training information used by women ultrarunners are presented in Table 2. Participants were asked two multiple choice questions in which they checked all the sources from which they receive information. The most frequent source of training information for these women was personal knowledge and experience (86.9\%) and the least frequently used source of information was a coach (25.4\%).

\section{[Insert Table 2 about Here]}

Participants were given an option to indicate other sources of training information in a short answer section if it was not included in the above list. Many women indicated that they sought training information from friends (e.g., other ultrarunners and/or the ultra list serve mentioned previously), books, and ultrarunning blogs.

The final question regarding training behaviors related to coach utilization. Most women (79.6\%) did not use a coach for training while only $20.4 \%$ did use a coach. When asked to explain why they chose not to use a coach, three themes were evident. The top reason why women did not use a coach was cost. Many women indicated that coaching was unaffordable for them. Some women said they would use a coach if they could afford to do so. The second most common reason women didn't use a coach was that they did not think they needed a coach. With all the training resources available, they felt having a coach was not a necessity. The least common reason women did not use a coach was because they felt that a coach would only be useful if they were training to win the race- not just to participate or finish.

The women who did work with a coach were asked to identify all the reasons they worked with a coach in a multiple choice question. They were then asked to identify the primary reason they work with a coach. Table 3 outlines the multiple choice answers and the percentage of participants who selected each reason, including their primary reason.

\section{[Insert Table 3 about Here]}

\section{Discussion}

This study described characteristics of women ultrarunners. Though ultrarunning has grown in popularity, its participants have not been studied extensively. For this reason, the present study took a holistic look at women ultrarunners by collecting data from multiple facets of their life; including demographic characteristics, motivation, goal orientations, training and coaching habits. 
The most important findings of this study were that (a) many of these women were able to train over 12 hours per week while working full time and balancing relationship and childcare responsibilities, (b) the strongest sources of motivation were health and achievement, (c) women were more task-oriented than ego-oriented, and most set goals for their events, and (d) coaches were not frequently utilized by this group of women, mostly due to the cost, but some women did not think they needed a coach.

For many women, time spent training for an event is almost a part-time job averaging just over twelve hours a week. It is important to note that the standard deviation was 5.2 hours, meaning some women train close to 20 hours a week; only two participants reported training fewer than six hours a week. In addition, most women trained with other people but spent over half their training hours by themselves. This is an expected finding due to ultrarunning being less popular than other individual sports and less inclusive of others when training distances become lengthy. A typical training run can exceed four hours. In addition, the training regimen itself is very challenging-- especially when trying to balance work, relationships, and parenting. Finding time to run often requires juggling schedules and running when the opportunity presents itself.

It is not surprising that $60 \%$ of women do not have children and that their spouses often participate in different sports. Although there are no data available to suggest how women balance training and life in the research from other ultra endurance sports, it is likely that it would become very difficult to have an ultrarunning spouse (unless the couple trained together) or young children.

Women ultrarunners were predominantly motivated to participate in ultrarunning events by personal achievement and general health. In addition, social recognition was minimally endorsed as a motive for running. Although ultrarunners rated the subcategory of weight concerns less strongly than other motivational factors in this study, and less strongly than other recreationally active women in previous studies $(8,9,11)$ it was still rated above a 4 , indicating that it is a motivator--just not one of the top motivators. Ultrarunning women also differed from women marathon runners and masters athletes who strongly endorsed social reasons for participation in events (14,20). Some of the motivational differences between participants in the present study and other women exercisers and competitors may occur because marathon running and other events attract a wide variety of people, and both genders are typically studied. In this case, ultrarunning women may be a more homogeneous population, thus their motivation for participation may be more similar in this population than it is in other women exercisers.

An unexpected finding was the strong endorsement of the main category of psychological motives. This finding makes intuitive sense because exercise is a cathartic behavior and is often used as a coping mechanism, a way find inner peace, and a self-esteem builder $(9,18)$. In addition, ultrarunning goes beyond what most people would consider standard exercise. Many ultrarunners experience a psychological and emotional reward for pushing themselves in extremely challenging situations. In her in-depth interviews with elite female ultrarunners, Harold (12) found that their narratives reflected a performance discourse that was "shaped by pushing the limits to finish as opposed to pushing the limits to achieve a fast time” (p. 169). Having the stamina to finish an event of that duration and intensity is bound to increase self-esteem in participants.

The finding that psychological motives were strong motivators is similar to results reported by Levy (18) who studied women mountain bike racers. She conducted a qualitative study that evaluated the meaning of competition for women mountain bikers. Levy found that all the women, without exception, highly valued the feelings of "esteem, personal growth, and personal challenge” they experienced as the result of racing. Women ultrarunners are motivated by the same experiences. It is possible that women ultrarunners endorse psychological factors as motivators, and that this is unique, but common in rigorous endurance sports.

Women ultrarunners had goal orientations that centered around task-mastery with components of ego-orientation verses solely a strong ego-orientation. An example from these data that supports this finding is that women set goals in three task-oriented categories: (a) to win (including age group placing), (b) to complete a challenge (e.g., complete a different course or new length or finish within a specific time), and (c) to have fun, finish the race, and remain pain and injury free. The task orientation of this sample of women is consistent with other studies done in multiple sporting contexts with all types of athletes from children to elite $(15,17,25)$. 
Ultrarunning, as of yet, is not a mainstream sport and therefore less information is readily available on how to train for an event. In addition, only a small amount of research in exercise physiology has been done on proper training techniques specific to ultrarunning. So the question remains, where do women obtain their information? In this sample, women relied on their own experience and on the ultrarunning community for their training information. Many women across the country stay in contact with each other through blogs, websites, and the Ultra List-serve and obtain training information in this way. Though there is no previous research to which women ultrarunners behavior can be compared, it seems they may be unique in that their connections to each other were enabled by the use of technology. The camaraderie they experience is unusual for people who are so geographically separated. The connection to each other may be partially behind the growth in numbers within the sport.

Most women chose not to use a coach and the main reason was the cost. The other reason women did not use a coach is they felt they could rely on their own experience and the ultrarunning community for guidance on training. Women who did use a coach felt the need for accountability and additional knowledge beyond their existing resources. Through their answers, women conveyed a disciplined approach to training with no need for outside accountability and they were happy with the performances they accomplished. Women who used a coach enjoyed the accountability but also said having someone else plan an exercise schedule, heart rate zones, and training variations made training more fun, and they did not feel "bogged down" by the science behind training. They could just go run. Based on the low prevalence of the use of coaching in this sample, and the benefits that are reported from women who do utilize a coach, it is clear that coaching is an untapped resource and further education of coaches could prove useful. If coaching became more available with less expensive options, and if coaching benefits were prominently featured, athletes and coaches could benefit.

This study has a few limitations that need to be acknowledged. First, the sample for this study was not obtained through randomization; therefore, the results may not be generalizable to the whole population of female ultrarunners. Second, because calls for participation were sent out without knowing how many total people might be reached, response rate cannot be quantified. Finally, because the MOMS motivation questionnaire has been used primarily with marathon runners, some motivational factors that are unique to ultrarunners may not have been included.

Despite its limitations, the present study provides information that enhances our understanding of women and ultrarunning. These women have proven to be unique, interesting, and inspiring and the surface has merely been scratched. For future work, demographic characteristics could be expanded to include socio-economic status, ethnicity, and level of education. With this additional information, many of these variables could be examined through a multivariate perspective as opposed the univariate approach taken in the present study. Because this study was broader in nature, additional studies that are more focused may yield additional information. In addition, future studies should grow more comparative in nature and include men as they are a key component of the sport and community. Many fascinating aspects of ultrarunning require a single purposeful analysis. Motivation is one specific aspect that could use further review. Questionnaires particular to ultrarunners and qualitative approaches could be used to explore motivation more deeply in this population.

One untapped area of research with this population is what contributes to success or deters from it. For example, do number of hours spent training, coach utilization, motherhood or work impact success? How is success defined by participants? Also, research should compare ultrarunning to other ultra-endurance sports such as 12 and 24 hour mountain bike racing and adventure racing. One final suggestion for future research is to repeat the study years from now to document how the present population (women ultrarunners) has evolved.

\section{Practical Applications}

It is amazing that only 42 years ago Kathrine Switzer was suspended from the American Athletic Union (AAU) for running the Boston Marathon because it exceeded the distance women were allowed to run (23). Today, women like Beverly Anderson (2007 U.S.A Track and Field Masters Ultrarunner of the Year), who in her 40s, is smashing course records for women and placed $2^{\text {nd }}$ three times in the Western States 100, the most competitive ultramarathon on record (7). 
The present study gives insight into these women so they can be better understood as people and athletes by those who know, work with, and coach them. Ultrarunning is a sport that has grown exponentially over the last twenty years and it shows no sign of stopping. To better understand current and future athletic racers, it is necessary that they no longer remain anonymous to the scientific and sporting community. In their ultrarunning endeavors, there will most likely come a time when they need to seek training help, coaching or even psychological assistance to improve performance and achieve new goals. If these athletes' motivations and goals are not understood, they cannot be adequately challenged and trained. As this study indicates, ultrarunners are geographically dispersed, and they often train and compete in solitude in wilderness locations, and tend to rely on technology (e.g., internet, GPS) to maintain communication and sustain community. This study offers another resource for this community of athletes (entry-level and veteran; novice and elite) to gain more knowledge and understanding of each other and their sport, whether that be for the purpose of improved training, motivation or performance. Therefore, both athletes and those who guide them will benefit from learning about and understanding the population. 


\section{References}

1. Abbas, A. The embodiment of class, gender and age through leisure: A realist analysis of long distance running. Leisure Studies 23: 159-175, 2004.

2. Acevedo, E, Dzewaltowski, D, Gill, D, and Noble, J. Cognitive orientations of ultra marathoners. The Sport Psyc 6: 242- 252, 1992.

3. American Ultrarunning Association (AUA). Retrieved October 20, 2008, from the AUA official website: http://www.americanultra.org/.

4. Baker, J, Yardley, J, and Cote, J. Coach behaviors and athlete satisfaction in team and individual sports. Int J Sport Psyc 34: 226-239, 2003.

5. Balaguer, I., Duda, J., Atienza, F. and Mayo, C. Situational and dispositional goals as predictors of perceptions of individual and team improvement, satisfaction and coach ratings among elite female handball teams. Psyc Sport Exerc 3: 293-308, 2002.

6. Beauchamp, M, Bray, S, and Albinson, J. Pre-competition imagery, self-efficacy and performance in collegiate golfers. J Sport Sci 20: 697-705, 2002.

7. Berge, M. Trail Running Going Green. Trailrunner 55: 43-44, 2008.

8. Bond, K. Running for their lives: A qualitative analysis of the exercise experience of female recreational runners. Women in Sport Phys Act J 14: 69-82, 2005.

9. Frederick, C, and Ryan, R. Differences in motivation for sport and exercise and their relations with participation and mental health. J Sport Behavior 16(3): 124-146, 1993.

10. Gill, D, Williams, L, Dowd, D, Beaudoin, C, and Martin, J. Competitive orientations and motives of adult sport and exercise participants. J Sport Behavior, 19: 307-318, 1996.

11. Gill, K, and Overdorf, V. Incentives for exercise in younger and older women. J Sport Behavior 17(2): 87-97, 1994.

12. Hanold, M. Beyond the marathon: (De)Construction of female ultrarunning bodies. Soc Sport J 27: 160-177, 2010.

13. Hockey, J. Injured distance runners: A case of identity work as self-help. Soc Sport J 10: 397-412, 2005.

14. Hodge, K, Allen, J, and Smellie, L. Motivation in masters sports: Achievement and social goals. Psyc Sport Exerc 9: 157-176, 2008.

15. Hodge, K, and Petlichkoff, L. Goal profiles in sport motivation: a cluster analysis. J Sport Exerc Psyc, 22: 256272, 2000.

16. Johnsgard, K. The motivation of the long distance runner. J Sports Med Phys Fit 25: 135-139, 1985.

17. Kuan, G. Goal profiles, mental toughness and its influence on performance outcomes among Wushu athletes. $J$ Sports Sci Med 6: 28-33, 2007.

18. Levy, S. Women and the personal meaning of competition: a qualitative investigation. Women in Sport Phys Act J 11: 107-119, 2002. 
19. Masters, K, Ogles, B, and Jolton, J. The development of an instrument to measure motivation for marathon running: The motivations of marathoners scale (MOMS). Research Quarterly in Exerc Sport 64: 134-143, 1993.

20. Masters, K, and Ogles, B. An investigation of the different motivations of marathon runners with varying degrees of experience. J Sport Behavior 18(1): 69-79, 1995.

21. Munroe-Chandler, K, Hall, C, and Weinberg, RA. Qualitative analysis of the types of goals athletes set in training and competition. J Sport Behavior 27: 58-74, 2004.

22. Myers, N, Vargas-Tonsing, T and Feltz, D. Coaching efficacy in intercollegiate coaches: Sources, coaching behavior, and team variables. Psyc Sport Exerc 6: 129-143, 2003.

23. Noakes, T. Lore of Running Champlain, IL: Human Kinetics, 675, 2003.

24. Ogles, B, and Masters, K. A typology of marathon runners based on cluster analysis of motivations. $J$ Sport Behavior 26: 69-85, 2003.

25. Pensgaard, A, and Roberts, G. Achievement goal orientations and the use of coping strategies among Winter Olympics. Psyc Sport Exerc 4: 101-116, 2003.

26. Roberts, G, Treasure, D, and Balague, G. Achievement goals in sport: the development and validation of the perception of success questionnaire. J Sport Sci 16: 337-347, 1998.

27. Smith, A, Ntoumanis, N, and Duda, J. Goal striving, goal attainment and well being: Adapted and testing the self-concordance model in sport. J Sport Exerc Psyc 29: 763-782, 2007.

28. Sternfeld B, Ainsworth, B. and Quesenberry C. Physical activity patterns in a diverse population of women. Preventive Med 28: 313-323, 2002.

29. Stoll, O, Wuerth, S, and Ogles, B. Zur Teilnahmemotivation von Marathon- und Ultramarathonlufern. [Participation motives of marathon- and ultra-marathon runners] Sportwissenschaft, 30: 54-67, 2000. 
Table 1

Motivation for Marathon Running Scale

Results in Women Ultrarunners

\begin{tabular}{|c|c|c|c|}
\hline Categories & $n$ & $M$ & $S D$ \\
\hline Physical health Motives & & 4.80 & 1.02 \\
\hline Weight Concern & 324 & 4.31 & 1.42 \\
\hline Health Orientation & 318 & 5.14 & 1.09 \\
\hline Achievement Motives & & 4.25 & 0.99 \\
\hline Competition & 316 & 2.88 & 1.40 \\
\hline Personal Achievement & 316 & 5.19 & 0.97 \\
\hline Social Motives & & 3.57 & 1.19 \\
\hline Recognition & 312 & 2.94 & 1.43 \\
\hline Affiliation & 319 & 4.19 & 1.37 \\
\hline Psychological Motives & & 4.74 & 1.00 \\
\hline Self-Esteem & 316 & 4.86 & 1.03 \\
\hline Life Coping & 317 & 4.69 & 1.23 \\
\hline Life Meaning & 312 & 4.58 & 1.37 \\
\hline
\end{tabular}

Notes: Higher score means stronger motivational reason. Categories in BOLD print are those with the highest scores. Sub-categories highlighted in GREY are those with the highest scores. 
Table 2

Sources of Training Information for Women Ultrarunners

\begin{tabular}{lcc}
\hline $\begin{array}{l}\text { Sources of } \\
\text { Training Information }\end{array}$ & $\begin{array}{c}\text { Percent of Each } \\
\text { Source Used } \\
(n=335)\end{array}$ & $\begin{array}{c}\text { Percent Used as a } \\
\text { Primary Source } \\
(n=314)\end{array}$ \\
\hline Personal knowledge and experience & 86.9 & 68.5 \\
Running magazine & 54.9 & 3.2 \\
Running website & 53.1 & 12.1 \\
Running club & 27.8 & 5.7 \\
Coach & 25.4 & 10.5 \\
I have a degree in exercise science & 4.5 & 0.0 \\
\hline
\end{tabular}

Table 3

Women Ultrarunners’ Reasons for Using a Coach

\begin{tabular}{lcc}
\hline & $\begin{array}{c}\text { Percent of Each } \\
\text { Reasons for } \\
\text { Coach Utilization }\end{array}$ & $\begin{array}{c}\text { Percent of Primary } \\
(n=82)\end{array}$ \\
\hline Training knowledge & 87.8 & $\begin{array}{c}\text { Reason a Coach is Used } \\
(n=74)\end{array}$ \\
Accountability & 51.2 & 64.9 \\
Motivation & 47.6 & 27.0 \\
Nutritional guidance & 26.8 & 10.8 \\
\end{tabular}

